\title{
Civil risk manager at European level
}

\author{
F. Russo \& C. Rindone \\ Dipartimento di Ingegneria dell'Informazione delle Infrastrutture e \\ dell'Energia Sostenibile, DIIES, Università degli Studi Mediterranea di \\ Reggio Calabria, Italy
}

\section{Abstract}

The purpose of this paper is to propose a standard process for training and certification to identify at European level a civil risk manager, with a common background.

An analysis of possible training and education activities in emergency planning at an international level is shown. Among preparedness activities, in this paper we consider activities that contribute to reducing the exposure risk components. The dangerous goods transportation risk is considered as a reference case, analyzing standard training and the certification process introduced by the United Nations and adopted at an international level. The experiences of the USA, the EU and Italy, in the context of civil risk training, are reported.

It is possible to reduce the exposure risk component implementing training activity to increase the capability of subjects involved in emergency conditions. Experiences of the USA and the EU relative to training constitute different attempts to certificate training in emergency planning. However, there is a lack of international standards to certificate a professional expert that can manage disaster in a standard way. It is possible to introduce training and certification for an EU civil risk manager adopting the United Nations' model concerning dangerous goods transportation.

In this paper, the necessity to implement training activities at different levels to reduce risk is highlighted. A possible trend of a risk level function depending on training activities' implementation at the time is proposed. However, in further studies, the function could be specified and calibrated referring to a model and specific surveys.

This study, in the context of analysis related to the standardization process in emergency planning, is the first proposal, to the authors' knowledge, into the 
introduction of standard vocational training and an international certification process for civil risk managers.

Keywords: civil risk, planning, training, certification, standard.

\section{Introduction}

In recent years, within the sustainable development topic, the United Nations (UN) introduced disasters in relation to their economic and human impacts. The UN's office for disaster risk reduction indicates that over the last twenty years, it is conservatively estimated that disasters have killed 1.3 million people, affected 4.4 billion and resulted in economic losses of $\$ 2$ trillion. These are costs' measures of inaction on climate change and risk reduction [1].

Disaster risk reduction refers to activities that aim to limit the impacts of a dangerous event. United Nation adopts International Strategy for Disaster Reduction (ISDR) starting from systematic efforts to analyse and reduce the causal factors of disasters. Reducing exposure to hazards, lessening vulnerability of people and property, wise management of land and the environment, and improving preparedness for adverse events are all examples of disaster risk reduction. ISDR is adopted to pursue four objectives: increase public awareness to understand risk; obtain commitment from public authorities to implement disaster risk reduction policies and actions; stimulate interdisciplinary and intersectorial partnership; improve scientific knowledge about disaster reduction [2].

At an international level, disaster risk reduction activities, can be synthetized as defined by four serial activities [3-5]: mitigation, comprising activities carried out in advance of an emergency event (e.g. land management and planning; public information campaigns); preparedness, comprising activities to ensure, if an emergency occurs, that communities, resources and services are capable of responding to the effects (e.g. evacuation planning; exercising, training and testing of emergency service staff $[6,7]$; response, including activities to control, limit or modify the emergency and to reduce its consequences (e.g. implementation of emergency plans and procedures in response to emergency incidents and provision [8,9]; recovery (community), including activities to support reconstruction of physical infrastructure after emergency situations (e.g. restoration of essential services, temporary housing; long-term medical care).

Considering a specific event, these activities can be organized respect to the period (time slice, $\Delta$ ) over which the event evolves; then four main intervals can be defined $\left(\Delta_{0}, \Delta_{1}, \Delta_{2}, \Delta_{3}\right)[10]$ :

- $\Delta_{0}=\left(\mathrm{t}_{0}, \mathrm{t}_{1}\right]$ between the times

$\mathrm{t}_{0}$, the time when the study of the evacuation plan is started;

$t_{1}$, the time when the hazardous event is known to happen or supposed forecasted;

in this interval mitigation and preparedness activities can be implemented; 
- $\Delta_{1}=\left(\mathrm{t}_{1}, \mathrm{t}_{2}\right]$ between the times $\mathrm{t}_{2}$ and $\mathrm{t}_{3}$, the time when the threat occurs and becomes a dangerous event and starts its effects; in this interval response activities can be implemented;

- $\Delta_{2}=\left(\mathrm{t}_{2}, \mathrm{t}_{3}\right]$ between times $\mathrm{t}_{2}$ and $\mathrm{t}_{3}$, the time when the final effect occurs and people cannot be rescued;

in this interval response activities can be implemented;

- $\quad \Delta_{3}=\left(\mathrm{t}_{3}, \mathrm{t}_{4}\right]$ between times $\mathrm{t}_{3}$ and $\mathrm{t} 4$, the time when the hazardous event ceases its effect on the population;

in this interval recovery activities can be implemented.

In recent years, much effort has been spent in preparedness activities at an international level. The USA National Incident Management System (NIMS) considers preparedness as a continuous cycle of planning, organizing, training, equipping, exercising, evaluating, and taking corrective action in an effort to ensure effective coordination during incident response [11]. Training activities assume a relevant role in the context of preparedness; for instance United Nation promotes education programs and training on disaster risk reduction in schools and local communities. The entire community must know about the hazards and risks to which they are exposed if they are to be better prepared and take measures to cope with potential disasters. Awareness, education and capacity building programs on disaster risk and mitigation measures are key for mobilizing citizen participation in the city's disaster risk reduction strategies. This will improve preparedness and help citizens respond to local early warnings [12].

Among preparedness activities, in this paper we consider activities that contribute to reducing the exposure risk component. We consider the specification in which the risk is obtained from the product of three main components: occurrence of an event; vulnerability involved land system; exposure calculated as the equivalent homogeneous weighted value of people, goods and infrastructures affected during and after the event [13].

For disastrous events with delayed approach, activities to reduce exposure are included in the set of preparedness. These activities can be classified into homogeneous classes in terms of execution time and decision-maker of single activities: activities related to material infrastructures (e. g. interventions on physical characteristics); non-material activities (e. g. interventions on learning and training or on Intelligent Transportation Systems) ([14, 15]); activities related to equipment (e. g. interventions to acquire tools and specific transport means); management activities (e.g. interventions to design transportation services) [16-20]; governance and institutional activities (e.g. interventions to regulate the transportation system).

Training activities are specific of non-material; these activities can be classified in two macro classes [21]:

- $\quad$ discussion-based activities, to discuss between trainer and participants about current plans, policies, agreements, and evacuation procedures; 
- operation-based activities, to simulate, in an operational context, a real emergency situation and to implement plans, policies, agreements, and evacuation procedures.

In the context of operation based activities training, European Union has organized in several state members simulation exercises to accelerate response in major emergencies. These exercises provide a learning opportunity for all actors involved in operations. Planning, decision-making procedures and provision of information to the public are tested during these exercises to prepare for similar real-life situations. Exercises constitute a support to identify training needs and operational gaps to be improved [22].

In Figure 1 is presented the standard training activities classification in the USA, introduced with Homeland Security Exercise and Evaluation Program (HSEEP) by the National Preparedness Directorate (NPD) [23]. HSEEP is a capabilities and performance-based exercise program that provides a standardized methodology and terminology for exercise design, development, conduct, evaluation, and improvement planning [24].

In literature there are limited researches that analyze how training reduces risk level. Training impacts in the functioning of the organization's emergency operations centre during a crisis are investigated in Sinclair et al. [25].

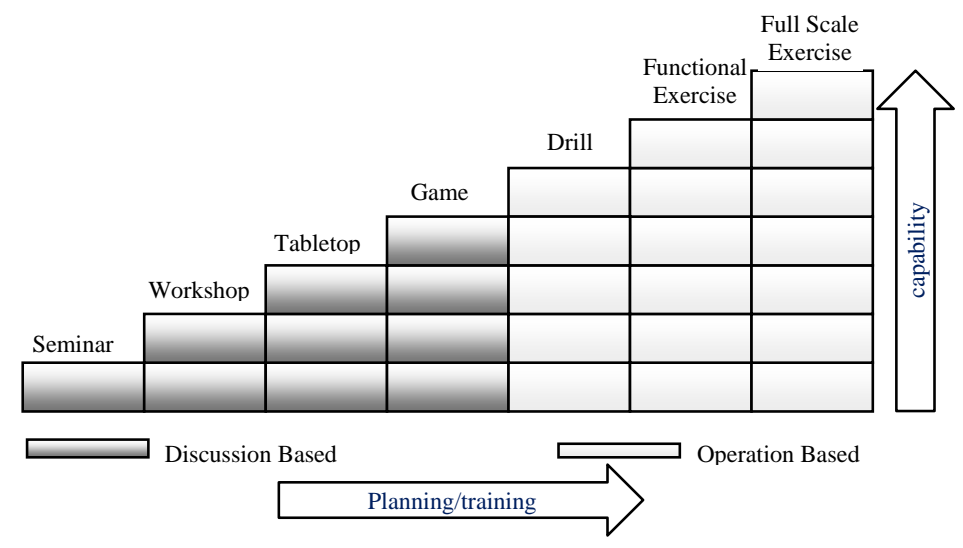

Figure 1: $\quad$ Training activities classification (source: [24]).

It is possible to suppose that a quantity of risk reduction can be obtained for each training activity.

If we indicate with $\mathrm{R}_{01}$ the risk level in the time $\tau_{01}$, inside the time slice $\Delta_{0}$ we can obtain a reduction of this level developing training activities.

For each activity i, Seminar, Workshop, ..., we can reduce the risk of a quantity $\Delta \mathrm{r}_{\mathrm{i}}$, where $\mathrm{i}$ is the generic training activity.

To simplify with a graphic presentation (Figure 2), we suppose that for each activity $\mathrm{i}$ the reduction is constant and it is equal to $\Delta \overline{\mathrm{r}}$; then:

$$
\Delta \mathrm{r}_{\mathrm{i}}=\Delta \overline{\mathrm{r}} \quad \forall \mathrm{i}
$$


If we develop a set I of activities during the time $\left(\tau_{01}, \tau_{02}\right]$ the risk reduction is:

$$
\Delta \mathrm{R}_{12}=\Sigma_{\mathrm{i} \in \mathrm{I}} \Delta \mathrm{r}_{\mathrm{i}}=\Sigma_{\mathrm{i} \in \mathrm{I}} \Delta \overline{\mathrm{r}}
$$

If any other activity is conducted, in the considered time period, the risk in the time $\tau_{02}$ is:

$$
\mathrm{R}_{02}=\mathrm{R}_{01}-\Delta \mathrm{R}_{12}
$$

A possible trend of a risk level function, inside the period $\Delta_{0}$, is presented in Figure 2, where a constant risk reduction for each training activity is hypothesized. Risk level decreases from the value $R_{01}$ to the value $R_{02}$.

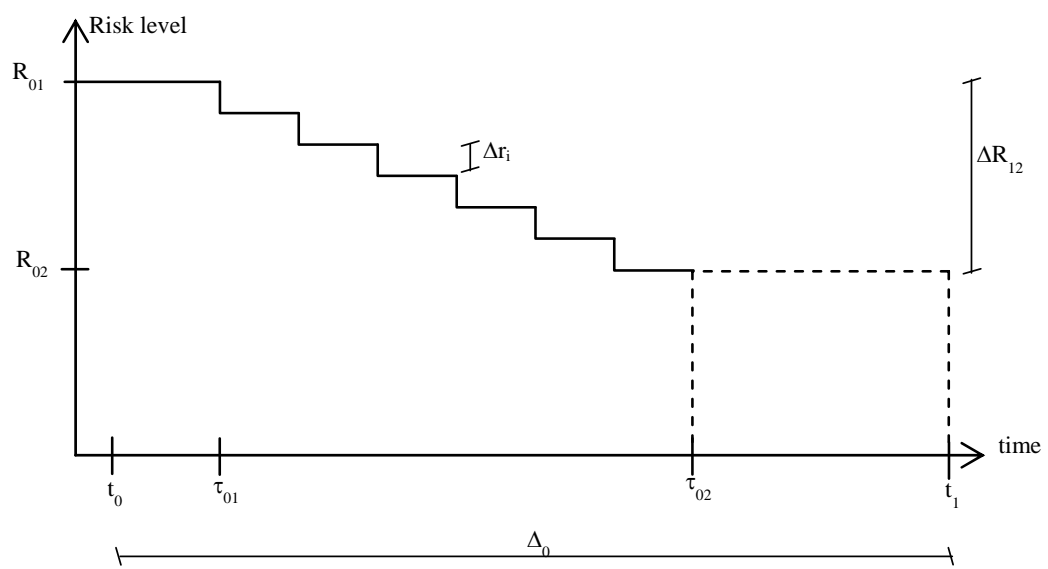

Figure 2: $\quad$ Risk reduction with preparedness activities.

From these considerations, it emerges the necessity to implement training activities at different level. Two possible reference levels are:

- base level that produces a professional certificate training released at national level;

- university level that produces a master or degree certificate training according to national laws.

Alexander [26] highlights a lack of homogeneity, consistency and quality control in emergency planning. For this reason, a set of criteria needs upon which standard professional in emergency planning might be based. These lacks are complementary to the asked level, then in section 2 we consider, the specific risk for dangerous good transportation: training and certification are analyzed. This case is presented how example of (inter)national professional certification. The USA, EU and Italian experiences are recalled.

In section 3, the current contents of civil risk management training is analyzed. Experiences of basic and university training levels in the USA and EU 
are recalled. In section 4 a feasible process to introduce training and certification of a civil risk manager is proposed.

\section{Dangerous good transportation training and certificate}

The United Nations set down recommendations on how dangerous goods should be transported to reduce risk and then to increase safety. The United Nations every two years publish recommendations which are then adopted by the governs for each modal regulation. These recommendations are not mandatory in law until they are adopted in the dangerous goods regulations below Recommendations on the transport of Dangerous Goods - Model Regulations, known as The Orange Book [27].

In the set of international experiences to certify Dangerous Good Safety Advisor (DGSA), according to United Nation indications, the selected references are USA (section 2.1) and EU (section 2.2).

\subsection{The USA experience}

The USA Pipeline and Hazardous Materials Safety Administration (PHMSA) provide education and training programs designed to increase expertize in dangerous good transportation. These programs build on cooperative linkages between industry, academia, professional associations and government at all levels [28].

The USA federal hazardous materials transportation law regulates the transportation of hazardous materials (hazmat) in the United States. This law requires the training of all hazmat employees. The purpose is to increase a hazmat employee's safety awareness and be an essential element in reducing hazmat incidents. The Hazardous Materials regulations (HMR) define training requirements that a hazmat employer must have: on the safe loading, unloading, handling, storing, and transporting of hazardous material and emergency preparedness for responding to an accident or incident involving the transportation of hazardous material. After completing the training, each hazmat employer shall certify, with documentation the Secretary of Transportation may require by regulation, that the hazmat employees of the employer have received training and have been tested on appropriate transportation areas of responsibility [29].

\subsection{The EU and Italian experiences}

The European Union requires Member States to implement legislation for introducing DGSA for transport of dangerous goods by road, rail and inland waterways, including the phases of loading and unloading [30,31]. The regulations prohibit the transport of dangerous goods by road and rail both within the State and internationally in Europe by companies which have not been appointed a DGSA.

A DGSA shall hold a vocational training certificate appropriate to the modes of transport and to the dangerous goods classes. The certificate shall be issued by 
the competent authority after a training course and by passing an examination approved by a competent state authority.

The aim of the training is to provide a sufficient knowledge of the risks inherent in the carriage of dangerous goods, of the laws, regulations and administrative provisions applicable to the modes of transport.

The aim of examination is to verify whether candidates possess the necessary level of knowledge to carry out the duties incumbent upon a safety adviser.

The examination consists of a written test which may be supplemented by an oral examination. The written test consists of two parts: in the first part the candidate has to fill a questionnaire that includes 20 open questions covering subjects' regulation about transportation of dangerous goods; in the second part the candidate shall undertake a case study in order to demonstrate that he has the necessary qualifications to fulfill the task of adviser. The certificate is mutually recognized in member States of the European Community. The certificate is valid for five years. The period of the validity is extended passing an examination [32].

In Italy, according to EU requirements, the law that receipted the rules to define and to qualify Italian DGSA, was approved and published in 2000. The Italian DGSA must have a vocational training certificate issued by the state Transport Ministry, after passing an examination according to European regulations. Firms, indicated in national law, must appoint one or more advisers. The adviser must prepare an annual report for the firm responsible. In the case of accident during the loading, carriage or unloading of dangerous goods that affects the health or safety of any person or causes damage to the environment, the adviser must prepare a report about the accident for the firm responsible and for the state Transport Ministry [33].

The Italian DGSA certificate, like the European adviser certificate, has to be renewed every five years after passing an examination.

\section{Civil risk management training}

In the set of international experiences in training to certificate civil risk manager capabilities we consider the USA (section 3.1) and EU (section 3.2) study cases.

\subsection{The USA experience}

\subsubsection{Master and degree programs}

In the USA, emergency management degree programs are available in universities and schools.

Federal Management Emergency Agency (FEMA) is a part of DHS that ensures that the single state improves the capability to prepare for, protect against, respond to, recover from, and mitigate all hazards. The FEMA approach [24, 34, 35] defines a continuous cycle process made by five modules:

- planning is a process consisting of logical steps to identify a mission or requirement, develop, analyze, and compare alternate courses of action, select the best practice of action, and produce a plan [36]; 
- training and education is a process that concerns, how teaching what to think and what the answers ought to be (training) and all about teaching how to think and what the questions ought to be (education);

- exercise is a process to train for, assess, practise and improve performance in prevention, protection. response and recovery capabilities in a risk-free environment [37]; exercises include discussion based exercises and operations based exercises;

- evaluation is a process of examining, measuring and/or judging how well an entity, procedure, or action has met or is meeting stated objectives [38];

- improvement is a process by which the observations and recommendations recorded are resolved through development of corrective actions [34].

FEMA National Training Program provides training, education and exercises by four institutes: Center for Domestic Preparedness (CDP), Emergency Management Institute (EMI), National Training and Education Division (NTED) and National Fire Academy (NFA). Among these EMI established in 1994 Emergency Management Higher Education Program (EM Hi-Ed) to encourage and support the dissemination of hazard, disaster, and emergency managementrelated information in colleges and universities across the United States. This program aim to institute emergency management higher education by: doctoral programs; masters programs; bachelors programs; associate programs (community, technical and junior colleges) [35].

For instance, the George Washington University Institute for Crisis, Disaster and Risk Management (ICDRM) propose: a Master of Science (MS) in Engineering Management with a concentration in Crisis, Emergency and Risk Management; a Graduate Certificate in Homeland Security Emergency Preparedness and Response; a Graduate Certificate in Emergency Management and Public Health; a Professional Degree (Engineer or Applied Scientist); Doctorate of Philosophy (PhD) in Engineering Management [39].

\subsubsection{Disaster risk manager certification}

The International Association of Emergency Managers (IAEM), that is a nonprofit educational supported by FEMA, has created two subsequent certification levels to raise and maintain professional standards: the first level is Associate Emergency Manager Programs $\left(\mathrm{AEM}_{\mathrm{SM}}\right)$; the second and higher level is Certified Emergency Manager ${ }^{\circledR}$ program $\left(\mathrm{CEM}{ }^{\circledR}\right)$.

$\mathrm{CEM}^{\circledR}$ and $\mathrm{AEM}_{\mathrm{SM}}$ certification are obtained in a peer review process administered through the IAEM. Certification is maintained in five-year cycles. The process is followed by a $\mathrm{CEM}^{\circledR}$ Commission, which is composed of emergency management professionals, including representatives from allied fields, education, military and private industry [40].

The IAEM is a well-known professional and academic organization of Emergency and Disaster Professionals worldwide. The main goals of this organization are to protect human lives, assets, and the environment during disasters. In addition, the organization's principles are to providing information, networking, education, professional opportunities, and to advance the emergency management profession. 
The Emergency Management Accreditation Program (EMAP) is a standardbased voluntary accreditation process for US government programs responsible for coordinating prevention, mitigation, preparedness, response, and recovery activities for disasters. Accreditation is based on compliance with collaboratively developed national standards, the Emergency Management Standard by EMAP. The Emergency Management Standard by EMAP is designed as a tool for continuous improvement as part of a voluntary accreditation process for local and State emergency management programs.

Accreditation is open to all U.S. States, territories, and local government emergency management programs. Anyone can subscribe to receive standards and guidance materials [41].

\subsection{The EU and Italy experiences}

The European Civil Protection (ECP), by means of the Community Mechanism for Civil Protection (CMCP), has organized: a Monitoring and Information Centre (MIC); a Common Emergency and Information System (CESIS); a Training program.

The EU doesn't have a Federal Agency that gives specific indications to the States. Each State organizes its training and certification. The EU attention is given to define homogeneous knowledge in the case of pan-European risk, or great national risk that involves, in the operative actions, people arriving from different states.

The courses offered by the European Community Civil Protection Mechanism Training Program presents a wide range of opportunities for civil protection experts.

The European training program has been set up with a view to improving the co-ordination of civil protection assistance interventions by ensuring compatibility and complementary between the intervention teams from the participating states.

The program involves training courses, joint simulation exercises and an exchange program, where experts can learn first-hand about similar responsibilities under different national systems [22].

The principal aim of training courses consists in preparing experts for international civil protection assistance interventions inside as well as outside Europe. A certificate is handed out at the end of each course providing the participant has attended the entire course.

Candidates conclude their preparation with a certification test, sometime useful to gain admission to the next course.

Every year the course program is updated, with new modules and new specific courses. It is possible, however, to schematize three different levels.

Introduction level. Different courses can be attended. The preliminary is the Community Mechanism Introduction Course (CMI) that provides generic information about the EU Civil Protection Mechanism and actors in an international emergency environment inside and outside Europe.

Operational level. A multiplicity of courses are supplied that present main elements from information management to security and assessment mission. The 
starting one is the Operational Management Course (OPM) that provides the basics for graduates to function as a full member in an On-site Operational Coordination Centre (OSOCC - outside Europe) or coordination setting (inside Europe). The OPM course is open to those who are in possession of the CMI certificate and the Distance Preparation Certificate for the OPM.

Management level. Two main courses are actually defined. The High Level Coordination course (HLC) aims at experts who could be selected as members of a team that can be deployed by the European Commission to facilitate coordination assistance in emergencies. The final course is to obtain a Head of Team (HoT) during civil protections, that imply a heavy responsibility: from the internal team management and psychology and leadership to interact effectively with the media in stressful situations. The HLC course is open to those who are in possession of the of CMI, OPM certificates and the Distance Preparation Certificate for the HLC.

It is evident that even if the courses have an international finality, the contents can be very useful also in the national context.

Actually, it is not possible for individual national experts to sign up directly for a course.

In Italy, professional and high level training has been realized. Among these:

- $\quad$ the Ministry of Research has instituted safety engineering bachelor programs and master programs Safety Engineering master (LM-26 - safety engineering, [42]) mainly to industrial risk manager;

- $\quad$ the Centre for Studies E.Di.Ma.S. (Emergency and Disaster Management Studies), in collaboration with several Italian and European Universities, and linked with the IAEM internet platform, has activated two types of master's degrees [43]:

- $\quad$ master on Official of Disaster and Emergency Management ${ }^{\odot}$ (ODEM) that train an Emergency Junior Manager;

- $\quad$ Emergency Management of Civil Protection ${ }^{\odot}$ (EMCP) that train Emergency Senior Manager;

- the Disaster Manager National Association releases Emergency Manager Italian Certification (EMIC) to certify two professionals profile [44]:

- coordinator that is an expert capable to coordinate activities to support functions of local operations centers in emergency conditions;

- planner that is an expert capable to examine and to draw up emergency plans, to provide consultant activities and to support civil protection authorities.

\section{A process for training and certification of civil risk manager}

From previous analysis, it emerges the relevance of training in evacuation planning. The USA and EU experiences presented in section 3 show that different attempts to certificate training in emergency planning has been tried. However there is a lack of international standards to certificate a professional expert that can manage disaster in a standard way. 
In recent years some proposal of standardization in risk management was introduced. The International Organization for Standardization (ISO) has published guideline for incident preparedness and operational continuity management [45], principles and guidelines for risk management [46]. In these guidelines there is not a proposal to certificate a civil risk manager.

It is possible to hypothesize the training and the certification for an EU civil risk manager. The reference model could be United Nations' general provisions concerning dangerous good transportation [32], presented in section 2 of this paper.

In this way a possible civil risk training and certification process can be constituted of the following steps:

- manual adoption to collect standard operations of civil risk manager, the reference is the manual for transportation of dangerous good by road;

- $\quad$ subjects' definition to appoint a civil risk manager (public authorities);

- civil risk manager knowledge, competencies and relative responsibilities definition; the responsibilities can be similar to those of safety adviser defined in UN 1.8.3.3; the civil risk manager' activities, testified for instance in an annual report, comprehend:

- monitoring of risks that affect community and undertaken activities to reduce risk;

- advising in terms of corrective activities to reduce risk;

- examination procedures definition to obtain a vocational training certificate for civil risk manager; the procedures can be similar to those of safety adviser examination procedures defined in UN 1.8.3.11; the examination is intended to verify knowledge about responsibilities defined in previous steps;

- $\quad$ certificate validity and renewal definition; according to dangerous good transportation regulations (ADR) and IAEM provisions, the period of validity can be five years conditioned to passing another examination (validity and renewal of certificate).

\section{References}

[1] UN, United Nation's office for Disaster Risk Reduction, http://www.unisdr.org/who-we-are/what-is-drr, 2012 (last access January, 2012).

[2] UN, United Nation's office for Disaster Risk Reduction, 2012, http://www.unisdr.org/campaign/resilientcities/toolkit/essentials/view/7, (last access January, 2012).

[3] Australia Governments, Emergency Management Approaches, 2010, http://www.ema.gov.au/, (last access January, 2011).

[4] USA, DoT, DHS, Department of Transport, Department of Homeland Security, Report to congress on catastrophic hurricane evacuation plan 
evaluation, 2006, http://www.fhwa.dot.gov/reports/hurricanevacuation/ (last access January, 2011).

[5] EC, European Commission, European civil protection, 2012, http://ec.europa.eu/echo/civil_protection/civil/prevention_overview.htm (last access November, 2012).

[6] Marcianò F. A, Musolino G., Vitetta A., Within-day traffic assignment and signal setting in road evacuation: a procedure with explicit path enumeration. WIT Transactions on The Built Environment, Vol. 117, pp. 403-414, 2011.

[7] Russo, F. and Vitetta, A., Reverse assignment: calibrating link cost functions and updating demand from traffic counts and time measurements. Inverse Problems in Science and Engineering, 19 (7), pp. 921-950, 2011.

[8] Russo F. and Trecozzi M. R., Models for humanitarian logistics, WIT Transactions on Ecology and the Environment, Vol. 155, WIT Press, Southampton, 2012.

[9] Polimeni, A. and Vitetta A., Optimising waiting at nodes in time-dependent networks: cost functions and applications. Journal of optimization theory and applications, 156 (3), pp. 805-818, 2013.

[10] Russo F. and Chilà A., Dynamic approaches to demand model in evacuation conditions, WIT Transactions on The Built Environment, Vol. 111, Pratelli A. and Brebbia C. A. (ed.), WIT Press, Southampton, 2010.

[11] USA, FEMA, Federal Emergency Management Agency, 2012, http://www.fema.gov/national-incident-management-system (last access November, 2012).

[12] UN, United Nation's office for Disaster Risk Reduction, Essential Seven: Training, Education and Public Awareness, 2011, http://www.unisdr.org /campaign/resilientcities/toolkit/essentials/view/7 (last access January, 2011).

[13] Russo F. and Vitetta A., Risk evaluation in a transportation system. International Journal of Sustainable Development and Planning, 1 (2), pp. 170-191, WIT Press, Southampton, 2006.

[14] Polimeni, A. and Vitetta, A., The role of ITS in evacuation route optimization for emergency vehicles. WIT Transactions on Information and Communication Technologies, Vol. 44, pp.517-529, WIT Press, Southampton, 2012.

[15] De Maio, M.L., Musolino, G. and Vitetta, A., The role of ITS in evacuation route choice. WIT Transactions on Information and Communication Technologies, Vol. 44, pp. 503-515, 2012.

[16] Russo, F. and Chilà G., A sequential dynamic choice model to simulate demand in evacuation conditions. WIT Transactions on Information and Communication Technologies, Vol. 43, pp. 431-442, 2010.

[17] Russo, F. and Chilà, G., Safety of users in road evacuation: demand models. WIT Transactions on the Built Environment, Vol. 96, pp. 773-782, 2007. 
[18] Russo, F. and Chilà G., Safety of users in road evacuation: RP vs. SP surveys in demand analysis. WIT Transactions on the Built Environment, Vol. 101, pp. 703-713, 2008.

[19] De Maio, M. L., Musolino, G. and Vitetta, A., Traffic assignment models in road evacuation. WIT Transactions on Ecology and the Environment, Vol. 155, pp.1041-1051, 2012.

[20] Polimeni, A. and Vitetta, A., A procedure for an integrated network and vehicle routing optimisation problem. Procedia - Social and Behavioral Sciences, 54, pp. 65-74, 2012.

[21] Russo F., Rindone C., Trecozzi M.R., The role of training in evacuation. WIT transactions on information and communication technologies, Vol. 44, pp. 491-502, 2012.

[22] EC, European Commission, The European civil protection training programme, 2012. http:/ec.europa.eu/echo/civil_protection/civil/prote/ pdfdocs/Training\%20brochure.pdf, (last access December, 2012).

[23] USA, FEMA, Federal Emergency Management Agency, 2012 http://raining.fema.gov/, (last access December, 2012).

[24] USA, DHS, Department of Homeland Security, Homeland Security Exercise and Evaluation Program (HSEEP), 2007, https:// hseep.dhs.gov/ pages/ 1001_HSEEP7.aspx, (last access December, 2012).

[25] Sinclair H., Doyle E. E., Johnston D. M., Paton D., Assessing emergency management training and exercises, Disaster Prevention and Management, Vol. 21 Iss: 4 pp. 507- 521, 2012.

[26] Alexander D., Towards the development of standards in emergency management training and education, Disaster Prevention and Management, Vol. 14, No. 2, Emerald, pp. 158-175, 2005.

[27] UN, United Nation, UN Recommendations on the Transport of Dangerous Goods - Model Regulations, Seventeenth revised edition, 2011 http://www.unece.org/trans/danger/publi/unrec/rev17/17files_e.html (last access December, 2012).

[28] USA, DoT, PHMSA, Department Of Transportation (DoT), Pipeline and Hazardous Materials Safety Administration, Training Resources, 2012 http://www.phmsa.dot.gov/training, (last access December, 2012).

[29] USA, DoT, Department of Transportation, Federal hazardous materials transportation law, 1994 http://www.law.cornell.edu/uscode/text/49 /subtitle-III/chapter-51, (last access December, 2012).

[30] EC, European Commission, Directive 96/35/EC of the European parliament and of the council of 3 June 1996 on the appointment and vocational qualification of safety advisers for the transport of dangerous goods by road, rail and inland waterway, 1996.

[31] EC, European Commission, Directive 2008/68/EC of the European parliament and of the council of 24 September 2008 on the inland transport of dangerous goods, http://eur-lex.europa.eu/LexUriServ/LexUriServ.do? uri=OJ:L:2008:260:0013:0059:en:PDF, 2008.

[32] UN, United Nation, European Agreement concerning the International Carriage of Dangerous Goods by Road - ADR 2011, 2010 
http://www.unece.org/trans/danger/publi/adr/adr2011/11contentse.html, (last access December, 2012).

[33] Italian Government, Italian Law 40/2000, Attuazione della direttiva 96/35/CE relativa alla designazione e alla qualificazione professionale dei consulenti per la sicurezza dei trasporti su strada, per ferrovia o per via navigabile di merci pericolose, 2000, http://www.camera.it/ parlam/ leggi/ deleghe/ 00040dl.htm, (last access December, 2012).

[34] USA, FEMA, Federal Emergency Management Agency, National Preparedness Guidelines, 2007, http://www.fema.gov/pdf/emergency/nrf/ National_Preparedness_Guidelines.pdf, (last access January, 2011).

[35] USA, FEMA, Federal Emergency Management Agency, National Training Program, 2012, http:// www.fema.gov/ prepared/ train.shtm\#1 (last access December, 2012).

[36] USA, FEMA, Federal Emergency Management Agency, Developing and Maintaining Emergency Operations Plans, 2010, http://www.fema.gov /sites/default/files/orig/fema_pdfs/pdf/about/divisions/npd/CPG_101_V2.pdf (last access December, 2012).

[37] USA, FEMA, Federal Emergency Management Agency, HSEEP glossary, 2012, https:/hseep.dhs.gov/DHSResource/Glossary.aspx\#E (last access December, 2012).

[38] USA, DHS, Department of Homeland Security, DHS risk lexicon, 2008, http://www.dhs.gov/xlibrary/assets/dhs_risk_lexicon.pdf (last access December, 2012).

[39] GWU, George Washington University, 2012, http://www.gwu.edu/ icdrm/

[40] IAEM, International Association of Emergency Managers, 2012, http://www.iaem.com/certification/generalinfo/intro.htm

[41] EMAP, Emergency Management Assessment Program, 2012 http://www.emaponline.org/index.php?option=com_content\&view=article \&id=25\&Itemid $=28$

[42] Italian Government, Decreto Ministeriale 270/2004, 2004, http://www.miur.it/Miur/UserFiles/Notizie/2007/DMCdL_magistrale.pdf (last access March, 2012).

[43] E.Di.Ma.S., Emergency and Disaster Management Studies, 2012 http://edimas.net (last access March, 2012).

[44] AssDIMA, Associazione Italiana Disaster Manager, 2012, http:// www.associazioneitalianadisastermanager.it/1/certificazioni_emic_202706 5.html (last access March, 2012).

[45] ISO, International Organization for Standardization, Societal security Guideline for incident preparedness and operational continuity management - ISO 22399:2007, 2007, http://www.iso.org/iso/catalogue_detail? csnumber $=50295$ (last access March, 2012).

[46] ISO, International Organization for Standardization, Risk management Principles and guidelines - ISO 31000:2009, 2009, http://www.iso.org/ iso/catalogue_detail?csnumber=43170 (last access March, 2012). 